Article

\title{
Conflict Causes and Prevention Strategies at the Society-Science Nexus in Transdisciplinary Collaborative Research Settings: A Case Study of a Food Security Project in Tanzania
}

\author{
Juliane Schütt ${ }^{1, *}$, Katharina Löhr ${ }^{1,2} \mathbb{D}$, Michelle Bonatti ${ }^{1}$ and Stefan Sieber ${ }^{1,3}$ \\ 1 The Leibniz Centre for Agricultural Landscape Research ZALF e.V., 15374 Müncheberg, Germany; \\ katharina.loehr@zalf.de (K.L.); michelle.bonatti@zalf.de (M.B.); stefan.sieber@zalf.de (S.S.) \\ 2 Section Urban Horticulture, Institute for Horticultural Science, Humboldt University Berlin, \\ Lentzeallee 55-57, 14195 Berlin, Germany \\ 3 Department of Agricultural Economics, Humboldt University of Berlin, Rudower Chausee 16, \\ 10099 Berlin, Germany \\ * Correspondence: juliane_schuett@web.de
}

Received: 20 September 2019; Accepted: 5 November 2019; Published: 7 November 2019

\begin{abstract}
Collaboration between researchers and society is essential when addressing challenging 21 st Century questions. Such collaboration often comprises international, inter- and trans-disciplinary teams, as well as temporal constraints, resulting in inherently complex research projects. Although practitioners increasingly appreciate the value of bottom-up approaches, operational details are often overlooked. Further knowledge is necessary, especially about what might endanger project success. Using a food security project, this paper analyzes conflict experiences and prevention strategies between project members and local stakeholders through personal interviews and focus group discussions. Data for this case study was collected in four Tanzanian villages. This paper identifies multiple conflict drivers, including missing information transfers; diverging expectations; overlaps of field activities with seasonal farming activities; and obscure participant selection. Identified conflict prevention strategies include developing trust, reducing language barriers, and involving locals. Research practitioners, institutes, and hegemonic actors are responsible for ensuring that projects will not worsen the entered situation and negatively affect the community, adhering to the "do no harm" principle; therefore, it is vital to be aware and seek to improve international and collaborative research projects that actively involve local stakeholders. This paper supports the understanding of interacting with local communities in a food security context to support the development of innovative collaboration approaches and methods. Through collaboration, it is possible to find sustainable solutions to pressing issues.
\end{abstract}

Keywords: collaborative research; local stakeholder; food security; collaboration conflict; conflict prevention strategies; sustainable development; transdisciplinary; Tanzania

\section{Introduction}

Food insecurity, climate change, and increasing wealth inequity are examples of 21st Century challenges where sustainable solutions are needed to prevent suffering, as well as irreversible negative consequences and impacts for both natural and human systems [1-5]. A decrease in economic activities, negative effects for the health status of societies, shortages in food production, and effects on water supplies are all examples of negative consequences that must be urgently addressed $[5,6]$. 
Addressing these 21st Century challenges and complex issues requires both bottom-up research approaches at the science-society nexus and collaboration among researchers $[7,8]$. Water, energy, and food (WEF) nexus research and their hotspots emphasize the importance of including all connected actors to enable and promote integrative methods and approaches to secure, for instance, a sustainable food supply [6,9].

Water, energy, and food (WEF) system issues are multi-scale in nature, leading to the need to assess different perspectives at the national, regional, and local levels, as well as "involving a multiplicity of stakeholders" [6] (pp. 194,196). At the WEF nexus, areas or "hotspots" are different stakeholders involved. They differ in their nature, goals, decision making powers, value systems, and "the way they interact" [9] (pp. 2,6,7). Collecting data from multifaceted local communities allows for holistic approaches and a better understanding of interconnections [6,9]. The authors argue that comprehending the stakeholder landscape, i.e., how they interact and what their trade-offs are, facilitates the development of sustainable solutions within socio-techno-economic-political WEF resource nexus hotspots [9]. Collaboration with stakeholders can take place through different methods and levels of involvement. Direct engagement and data collection can be done through workshops, focus group discussions, surveys, questionnaires, and other participatory methods [9]. Finally, the authors stress that the process of reviewing, revising, and reworking approaches enables them to work more effectively toward the achievement of the sustainable development goals [9]. Thus, local stakeholders (LSs) are fundamentally important, and their cooperation is required to implement, perform, and complete collaborative research projects successfully. As LSs are core participants in these projects, with a high degree of involvement, any problems, challenges, and conflict affecting their collaboration might endanger project success.

Collaboration in research projects with local communities or local stakeholders is widely accepted as a "bottom-up" approach, since the people who deal with the issues under investigation may provide valuable information and insights $[7,10,11]$. Local stakeholders in this research are any individuals who have "any interest in the project and who may influence project planning, design, implementation and future use" [12] (p. 291). In this research, the term local stakeholder includes, among others, farmers, traders, consumers, and target family households. Mauser et al. [7] argued that collaboration across disciplines and alongside relevant societal groups is needed to understand complex sustainability challenges. Societal involvement provides supplementary inputs and the co-production of knowledge; i.e., that the involvement of non-academic actors is recommended in interdisciplinary research. This is supported by Löhr et al. [13], who also argued that involving and integrating knowledge and various perspectives creates value for collaborative research projects, thus increasing the relevance of LSs. This kind of research design incorporates local knowledge, local needs, and local interests.

To integrate the perspectives and knowledge needed to develop new and sustainable answers to global challenges, research projects, including collaborations at the science-society nexus, are typically characterized by international teams, inter- and trans-disciplinary actors, and multiple stakeholder involvement. The multi-actor environment results in inherently complex projects prone to conflicts $[8,13]$. Besides the challenge of transdisciplinary settings, research projects, particularly international and third-party funded research projects, often have budget and time constraints. Additionally, scientists usually become project coordinators by merit and not by professional training. Therefore, applied skills on project coordination, including human resource, as well as conflict management, are often less well developed than in other professional fields [8,14]. Despite rapid evolution of transdisciplinary and conflict management approaches, an understanding of practical operational details to implement these approaches in research is lacking. Also, in the context of transdisciplinary research projects, community perspectives are understudied so far. Further insights and knowledge about research collaborations are necessary, especially those threatening project success.

In this context, a large and growing body of literature investigates conflict in various settings. Thus, the term is used and defined in many ways [15-18]. Here, we apply the broad definition of conflict by Rahim [19], who defines conflict as "an interactive process manifested in incompatibility, 
disagreement, or dissonance within or between social entities" (p. 207). This broad definition of conflict avoids limiting the scope of the research by defining it as a process in which individuals become involved in the conflict at different levels [20]. This definition is purely interpersonal. However, task conflicts are considered in the analysis of the collected data, since task and relationship conflicts cannot easily be disentangled, as one often leads to the other [21].

Conflicts between LSs and project members (PMs) can endanger project success, as conflicts can be costly, potentially delaying, if not killing, a project [22]. Moreover, insufficient or poor data, delayed results or deliveries, and the absenteeism of PMs and/or LSs can disrupt projects [8]. Under third-party funding, time extensions and additional funding are difficult to receive [8].

This study analyses conflict drivers, as well as the mechanism that can prevent conflict in international, trans-, and inter-disciplinary research collaborations. Two research questions guide the development of this research: What causes conflict between local stakeholders and project members in a collaborative research project on food security? What strategies prevented conflict in the collaborative research project? By addressing these issues, the authors add to the existing literature: A structured case study analysis of conflict experiences in a food security project and show how the findings can be addressed by categorizing conflict causes into identified prevention strategies. Therefore, this research extends the previous knowledge about collaboration conflicts within an interdisciplinary and international science-society collaboration project by highlighting local stakeholders' voices about project failures as well as limitations to project implantation. With this research, an enhanced understanding of communities' needs and structures is revealed to avoid conflict and project failures for future endeavours. Scaling-Up Nutrition (Scale-N), a collaborative research project focusing on food security, is the case study. The project aim is to improve the food situation, meaning the availability of food, as well as teaching residents to consume a diverse diet, in four Tanzanian villages [23]. The project consortium comprises more than 22 scientists and non-scientists from multiple institutions and countries of origin [24]. The researchers have disciplinary backgrounds in the fields of nutrition, economics, agricultural economics, agronomy engineering, and development economics. Project members originate from different countries, including Brazil, Germany, Sweden, and Tanzania. This project was chosen as food security projects are often characterized by international teams, inter- and trans-disciplinary actors, and multiple stakeholder involvement; thus providing a suitable research context for analyzing conflict experiences.

\section{Conflict Drivers and Prevention Strategies}

Food security is a global challenge that needs to be addressed by the international community. International projects dealing with food security are typically characterized by a shortage of both time and funds, as well as multiple actors with both diverse institutional and disciplinary backgrounds. In addition, food security is a global challenge that requires the involvement of people "on the ground". With its inherently complex settings and active involvement of local actors, food security projects provide an ideal setting for evaluating collaboration conflict experiences; thereby adding to understanding practical operational details within these approaches, addressing an under-researched aspect in the current literature.

There are several reasons why and how conflict might occur. This literature review first summarizes conflict drivers that are discussed in the disciplines of organizational psychology, collaborative research projects, conflict management, and project management. These disciplines take into account relevant literature, as well as various facets of projects, including international, interdisciplinary, and community-based approaches. This literature review covers a broad range of disciplines, thus not pushing this research in a specific direction. Secondly, it takes contextual factors into account, identifying those that might trigger conflict in a research project focusing on food security in Africa.

The published literature agrees on three categories of conflict: cognitive conflicts, normative conflicts, and relationship conflicts [12,21,25]. Cognitive conflicts occur when two or more parties evaluate and interpret information or data in different ways, thus arriving at different conclusions. 
Normative conflicts are driven by different perceptions about norms, values, and manners; whereby the starting point for conflict is based on subjective moral principles. Relationship conflicts arise due to the behavior or personalities of the parties involved [12].

Other drivers discussed in the literature leading to conflict include: diverging objectives, views and/or interests; a resource shortage; uncertainty about authority lines and/or power imbalances; reward systems; time constraints; heterogeneity among the actors; a lack of explanations and inefficient communication; perceived injustice; unreliable and delayed information; as well as postponed meetings $[13,21,25-30]$.

The collaborative research literature, covering collaboration between researchers, as well as at the science-society nexus, also names conflict drivers: missing and unwritten instructions; diverging research concept methods; the gap between research and real life; funding constraints; competition over scarce and limited resources; lacking accountability; jealousies; lacking commitment from project and national implementers to involve local communities fully; risk that stakeholders are tired/demotivated of such projects; as well as ill-defined criteria for project selection and participation [13,29,31].

Additionally, in international working environments, conflicts may be driven by cultural differences, language barriers, and cultural prejudices [20,32,33].

A review of contextual factors highlights the collaborative conditions within which the Scale-N project was implemented. Much of the Tanzanian population (more than 80 percent) lives in rural areas and depends on agricultural production [34]. Under-nutrition and poverty are widespread and continue to be big issues [34]. Further, agricultural productivity is low with limited improvement and smallholder farmers dominating the market. These farmers, dependent on rain, have limited access to improved seeds and fertilizers [34]. Conflicts rooted in natural disasters, like floods and droughts, make food production challenging. Climate change is exacerbating the situation in many regions [35].

This literature review shows that international, multi-actor, and time limited projects are complex settings fraught with conflict drivers. Contextual factors of the research project, like severe food insecurity, poverty, limited access to markets, and natural disasters, may lead to a tense collaboration atmosphere, ultimately triggering conflict. Contextual factors must be considered since conflict drivers vary across project types and conditions. It is important to gather specific information about causes of conflict in collaborative research projects and to acquire insights about practical operational processes, thus helping project managers and researchers to become able to both consider and prevent them from the earliest planning stages of a collaborative research project. However, specific conflict prevention strategies for international, multi-actor, and interdisciplinary research projects are rarely a priority in the literature. These are mainly discussed indirectly or as an underlying part of research works.

Integrating conflict prevention strategies in project design is crucial as conflicts can negatively affect collaboration: Boa et al. [36] suggested for example problems, including violence, poor communication, increased uncooperativeness, and attention directed away from actual problems. Löhr et al. [20] emphasized that, in time-limited projects, it is important to engage in conflict prevention activities as early as possible. Moreover, preventing conflicts requires fewer resources than resolving them [37].

Conflict awareness and training, along with improving conflict management communication, are possible conflict prevention strategies [8]. Effective interpersonal communication skills are necessary to resolve conflicts successfully [36]. Furthermore, PMs should be aware that changes at the research site might occur and be prepared to react flexibly, adapting to such changes [38]. Furthermore, sensitizing the participants to potential issues, including cultural differences and language barriers, is a critical step [32,33].

\section{Materials and Methods}

\subsection{Case Study Description}

Scale-N seeks to improve the food situation in four Tanzanian villages by developing local solutions, testing strategies, and improving the understanding of local food insecurity [23]. LSs collaborated at 
differing levels of intensity. A variety of activities were implemented throughout the project. Contact and collaboration between LSs and PMs took place, for example, at sensitization workshops about the project; workshops to identify major problems related to food insecurity; discussing and developing possible solutions to identified problems; ongoing research activities; showing participants of the project how to produce organic pesticides and how to process and store food; building school gardens; setting up demonstration sites and teaching LSs how to build so-called "pocket-gardens" to grow vegetables. For setting up school gardens and building pocked gardens, materials (trees, bags, and seeds) were given to the project participants.

The overall concept of the Scale-N project is to use food value chains as an analytical framework to understand food systems fully and to define boundaries and components of food systems within a local context [39]. Further, an analysis of the nutritional status of villagers is part of the project's concept [40], implementing a collective learning approach to test innovative educational tools, whereby community voices are crucial. The Scale-N project commenced with a baseline study that collected data on the health status of all villagers from the four case study villages $(n=663)$, including height, weight, and determining their nutritional status with a blood sample. At the conclusion of the project, this study was repeated to analyze the impact of the food security activities. The National Institute for Medical Research Tanzania and the Ministry of Health, Community Development Gender, Elderly \& Children Tanzania granted ethical clearance for conducting this study. Interviewing participants was an integral part of the ethical clearance. All participants were informed that the interview material was to be used for scientific purposes, and their informed oral consent was given.

The Scale-N project was implemented in the Morogoro and Dodoma regions of Tanzania. These regions were selected due to their high vulnerability to food insecurity. There are diverse environmental and socio-economic conditions within these regions. From the Morogoro region, the villages Tindiga and Mhenda were selected; from the Dodoma region, Mzula and Chinoje were selected [23]. Participatory approaches drive numerous interactions at the stakeholder-scientist nexus. The input, ideas, and comments from the LSs were recognized as valuable since they have specific knowledge about the area and living conditions [23].

The Scale-N project was chosen as the case study because it has a high degree of local stakeholder involvement and it exemplifies the complex setting of international and transdisciplinary research collaboration projects. Additionally, the four Scale N-project villages were chosen to collect information on a variety of dynamics, environmental conditions, and interpersonal structures. This study focuses on Scale-N's PMs and LSs who are actively involved in the project. Identifying these PMs and LSs was done with the support of project coordinators from the Sokoine University of Agriculture (SUA), Tanzania.

\subsection{Methods}

This research adopted a participatory methodological design to better understand the realty lived by the project participants and the communities where the project was applied. Therefore, a key concept, problematization developed by Freire [41], guided this research. Problematization is an active, collective, and critical approach to a certain reality context [41], in this case the project implementation. It happens through a set of activities around the participants' reality and problems. In this notion, two qualitative data collection methods were combined to obtain a more holistic picture of the causes of conflict, as well as a variety of perspectives of experienced conflicts. The methods included (1) personal interviews and (2) focus group discussions (FGDs). In total, 127 persons were questioned about their conflict experiences, through (1) 43 personal interviews (13 with PMs and 30 with LSs) and (2) seven focus group discussions with a total of another 84 LSs. Table 1 displays the numbers of participating LSs per study village. Most data was collected during an 18-day site visit to the four study villages in February 2018. The personal interviews and FGDs with LS, as well as selecting the participants were supported by a translator and a facilitator. 
Table 1. Interviews and FGDs per village.

\begin{tabular}{ccccc}
\hline & \multicolumn{2}{c}{ Dodoma Region } & \multicolumn{2}{c}{ Morogoro Region } \\
\cline { 2 - 5 } & Village 1: Chinoje & Village 2: Mzula & Village 3: Tindiga & Village 4: Mhenda \\
\hline Personal Interviews (PI) & PI: 10 & PI: 7 & PI: 6 & PI: 7 \\
\hline \multirow{2}{*}{ Focus Group } & FGD 1: 10 & FGD 1: 12 & FGD 1: 14 & FGD 1: 14 \\
Discussions (FGD) & (Mixed) & (Females) & (Females) & (Females) \\
\cline { 2 - 5 } & FGD 2: 11 & FGD 2: 9 & FGD 2: 6 & FGD 2: 8 \\
& (Mixed) & (Males) & (Males) & (Males) \\
\hline
\end{tabular}

Source: authors' own illustration.

The age range of the total sample was between 21 and 70 years. There was no age limitation set before the study. At the end of each personal interview and FGD, participants received compensation, as well as cookies and a soft drink. The compensation was given for their time, for walking to the interview sites, and for leaving their daily farm work.

\subsubsection{Personal Interviews}

A semi-structured interview guide was designed to gather conflict experiences on a personal level and to obtain deeper insights. The semi-structured approach provided flexibility during the interviews and allowed reacting to the course of the conversation during the interviews. To allow for an open interpretation of the research topic, a definition of "conflict" was not provided to LSs and PMs during the personal interviews and focus group discussions. The semi-structured interview questionnaire was designed by using the SPSS method after Helfferich [42], i.e., collecting questions; checking the relevance and wording of the questions; sorting or categorizing the remaining questions into thematic blocks (by topic and type of question); the categorized and verified questions completed the interview guide [43]. Further inspiration for the design of the questionnaire was obtained from a former research dealing with conflict experiences within the research team. The questionnaire was developed by scientists based in Germany. However, Tanzanian project team members examined the questionnaire before data collection commenced to ensure the comprehensibility of questions and helped to adapt questions as needed.

The interview questionnaire was divided into three blocks of questions: The first block contained introductory and background questions (for instance: What is your role in the project? What was your first thought when you learned about the project?). The second block asked about conflict experiences (for instance: How would you describe your experience in working together with externals/LSs in general? When thinking about the collaboration with externals/LSs: Have you experienced any challenges/problems during the implementation phase of the project? What about the time after the implementation until now?). During the interviews, if the interviewee did not experience (m)any conflicts, it was also asked why there were rarely challenges or problems. This follow-up question helped identify strategies that prevent conflict from occurring. The last block dealt with coping strategies and recommendations (for instance: How did you deal with the described difficulties? What would have helped you to deal with the problems/challenges?).

The implementation of personal interviews included a two-person research team, each with their own research focus, and a translator who supported the researchers in communicating with the LSs. There was no translator needed during the personal interviews with PMs, since they were conducted in English. The personal interviews with LSs and PMs lasted on average 45 to $50 \mathrm{~min}$.

\subsubsection{Focus Group Discussions}

To complement the individual interviews that allowed more in-depth analysis, focus group discussions (FGDs) were conducted. The aim of the FGDs was to broaden the discussion on collaboration experiences and to verify the findings of the personal interviews. Two key areas of 
interest existed for the focus group discussions: (1) Have LSs encountered or experienced any conflicts with PMs in the course of the project collaboration? (2) Do the experiences of LSs overlap with the findings of the personal interviews that were conducted with LSs but also PMs? The FGDs were performed with LSs only and lasted between one and two hours.

The FGDs were implemented following a semi-structured approach. First, an introduction of the researchers, translators, and facilitators was done, followed by brief background information about the research itself. Rules for the FGD were introduced, like for example: (1) there is no right or wrong answer, there are only different points of view; and (2) everybody can speak, but only one person talking at a time. To increase participation and to prevent only a few dominant participants being heard, sign language was introduced. Participants were asked to raise their hand and signal their agreement or disagreement with what was discussed.

The questions for the FGDs were extracted from the personal interview questionnaire (cf. Section 3.2.1) to allow for comparison of results. Six key questions were extracted from the individual questionnaire guide and discussed in the FGD: (1) How would you describe your experience in working together with externals (PMs)? (2) When thinking about the collaboration with externals (PMs): Have you experienced any challenges/problems while working together with them i.e. during workshops/trainings/surveys? (3) What were the consequences of the challenges/problems? (4) How did you deal with the described difficulties? (5) What do you think could be improved in the collaboration of PMs and you? (6a) Have you noticed problems/troubles between participants of the project (Yes/No)? If yes: what kind of problems/troubles? (6b) Have you noticed problems/troubles between participants and people from the community who do not participate in the project? If yes: what kind of problems/troubles?

The location of the FGDs was either in a classroom inside the village school or outside in front of them.

School tables and benches were put in a U-shape, so that the participants could see each other; it also created an open atmosphere, where everybody could express themselves freely. At the first FGD, questions were mainly answered by the men, while the women remained rather quiet. Thus, recognizing that separating participants by gender might be beneficial, subsequent FGDs were conducted with separated genders.

\subsection{Analytical Approach}

The personal interviews and FGDs were recorded with the permission of all participants. Respondent's answers were transcribed in summary form. Notes taken during the research activities were also considered as analytical material. All data was analyzed using a qualitative content analysis [44,45]. In the first step, all pieces of information perceived as important, interesting, surprising, and repetitive were marked. In a second step, a codebook was designed on the basis of the marked and labelled data. From there, broad categories aligned with the research question were identified. Lastly, the identified categories (e.g., organization) were refined and further subdivided into subcategories as presented and discussed in the subsequent sections.

\section{Results}

This study aims to identify (1) conflict causes between LSs and PMs, the main involved actors at the operational level of a transdisciplinary food security project, and (2) strategies that can prevent conflict. The results presented include, first, an overview of identified conflict causes of all four villages and, second, strategies preventing conflict. Although the identified conflict causes were heterogeneous and diverse, they were often interconnected. The findings of the personal interviews and focus group discussions largely overlapped. 


\subsection{Conflict Causes at the LS-PM Collaboration Intersection}

Our study found numerous challenges that can impact negatively the collaboration of local stakeholders (LSs) and project members (PMs) when working together on a project on sustainable development. To present the variety of results in a structured way that also helps the reader to understand them better, fishbone diagrams were used. The fishbone diagrams 1, 2, and 3 summarize all results presented in this section. Conflict causes identified by this study are presented in the upper part of the diagram and resulting conflict consequences in the lower part. Findings are grouped into four categories, each referring to a different key driver of conflict:

1. Organization: material, people, and information (Figure 1);

2. Interculturality: language and tradition (Figure 2);

3. Perceptions: expectations and selection (Figure 2); and

4. Environment: nature, infrastructure, and livelihoods (Figure 3).

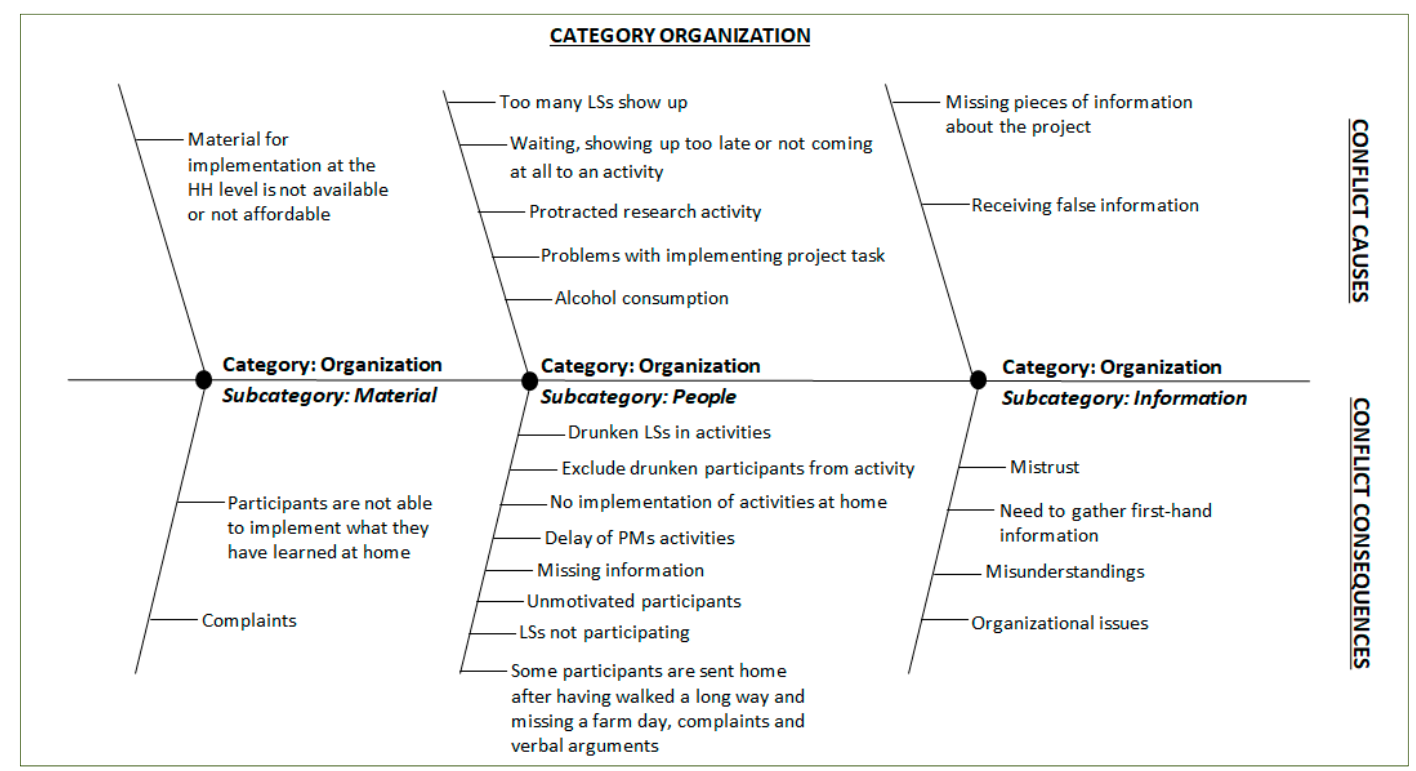

Figure 1. Conflict causes and consequences between local stakeholders (LSs) and project members (PMs): organization. Source: Own Findings [46].

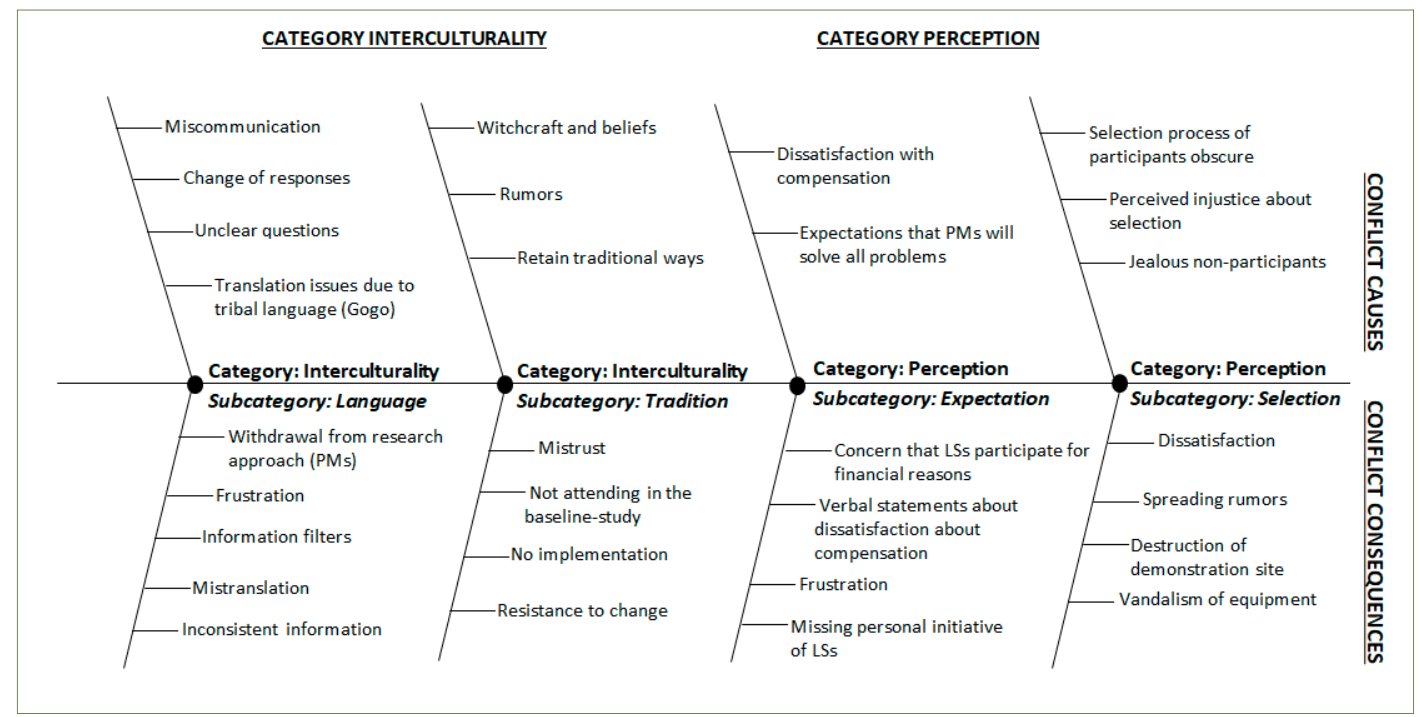

Figure 2. Conflict causes and consequences between LSs and PMs: interculturality and perceptions. Source: own findings [46]. 


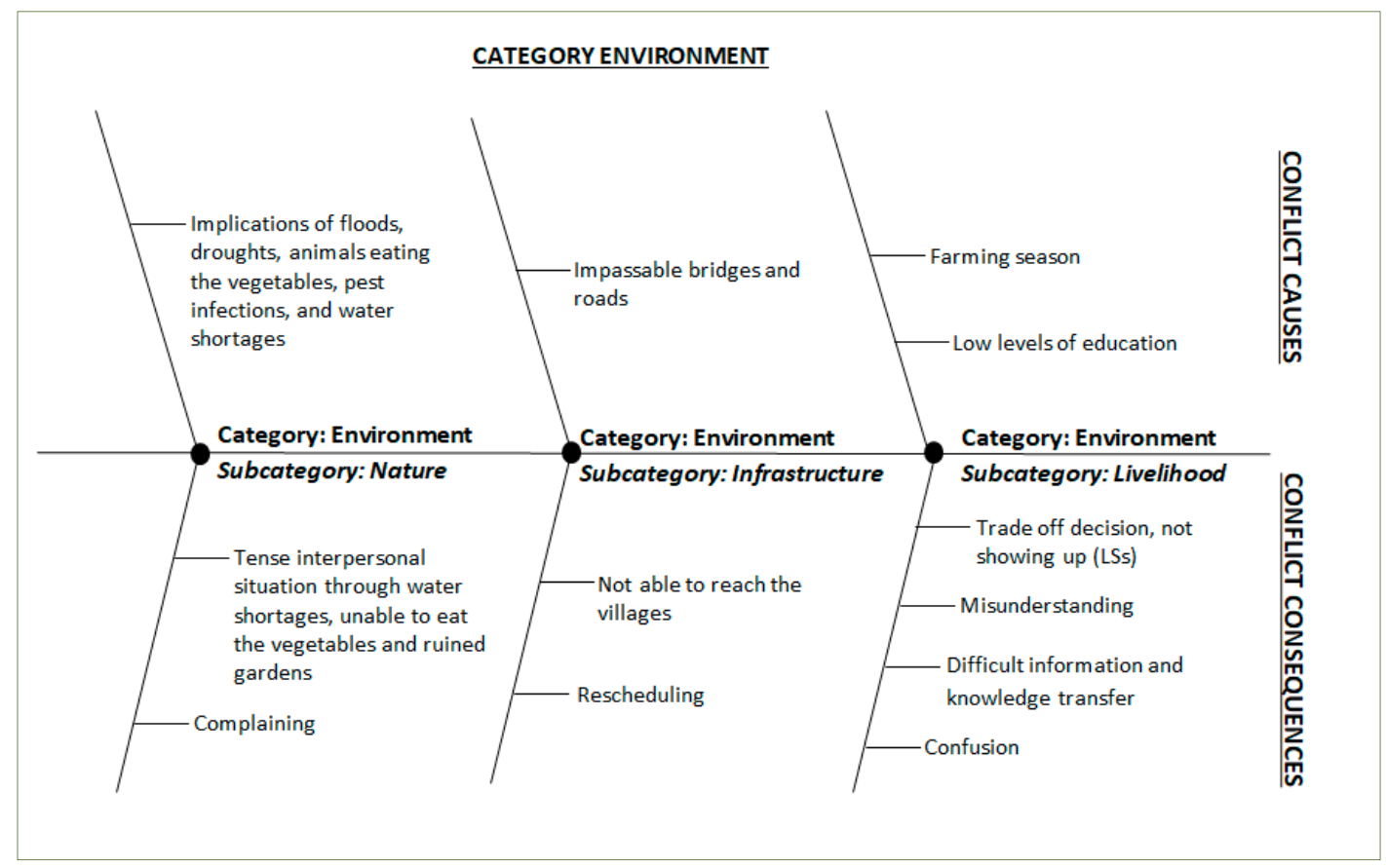

Figure 3. Conflict causes and consequences between LSs and PMs: environment. Source: own findings [46].

\subsubsection{Category: Organization}

Material: Some LSs identified materials (to build pocket-gardens) as a cause of conflict as they are sometimes unavailable or unaffordable for some, thus preventing food-security upgrading strategies from being implemented at the household $(\mathrm{HH})$ level. The intended knowledge transfer is not put into practice in these cases, and there is no information if the food-security upgrading strategies work or not. Here, LSs were frustrated and reported about implementation difficulties. This conflict was present for LSs in all four villages.

People: Participants linked conflicts to people's behavior, for example in cases when LSs or PMs did not show up to meetings or events, implemented project activities with delay, or protracted research activities. This point also incorporated conflict arising because too many LSs wanted to participate in the project/research activities, thus resulting in some being sent home. LSs walk a long distance to reach village centers, missing a whole day of farm work during farming season. Therefore, they demonstrated their anger about being sent back home verbally. In the Dodoma region, i.e., Chinoje and Mzula, several informed households told neighbors when PMs were visiting, resulting in too many LSs showing up for an activity. This conflict cause was primarily mentioned by PMs. Alcohol consumption was noted as a conflict driver by PMs. For example, one PM stated that during some visits, "half of the villagers are drunk, especially on market day." Training and interviewing drunken LSs is not meaningful for the research. The production and consumption of alcohol is common in these rural areas, especially during the non-farming season.

Information: Conflict was caused by a lack of transparency for LSs about the project itself. LSs did not know when the project would end and did not receive basic information about it; a conflict present in all four villages. Receiving false information was identified as another dysfunctional conflict cause by PMs. An example of false information, provided by a PM, was that "on the telephone they tell you everything is fine, but when you go there you see a lot of problems."

The following Figure 2 shows the categories interculturality and perceptions. 


\subsubsection{Category: Interculturality}

Language: Language barriers were identified as a source of conflict during field trips, especially for foreign project members. In this case, international researchers (PMs) were unable to gather first-hand information from stakeholders as they always needed a translator to communicate in Swahili or other local languages. The use of translators and local researchers could not eliminate all language barriers, as some LSs only spoke Gogo, a tribal language.

Traditions: Project members reported that traditions affected their research activities. The Scale-N study included a blood test in its baseline study. This resulted in rumors within the case study villages. For instance, the "white" people take the blood collected during the aforementioned baseline study to create diseases. These rumors caused several LSs to not participate in the baseline study at the start of the project. In both regions, Dodoma and Morogoro, rumors triggered conflict. This subcategory also incorporated conflict caused by some LSs who resisted changes due to rather rigid traditions.

\subsubsection{Category: Perception}

Perception: LSs perceived externals as "experts" who were able to quickly solve their problems. According to one PM, "they [LSs] expect you to come and do everything". This conflict was especially present in the Dodoma region, i.e., Chinoje and Mzula. The conflict cause was rooted in diverging perceptions, as PMs expected LSs to be active in the project. This conflict cause was primarily derived from the responses of PMs.

Expectation: LSs were dissatisfied with the compensation amount. According to several LSs from the Morogoro region, the amount was not sufficient compared to the time spent on a research activity. Some LSs stated that they would withdrawal from the project if the compensation amount was not increased. In contrast, PMs regarded it unethical to pay the project beneficiaries, voicing the concern that some LSs might only participate because of the compensation, thus trying to satisfy the researcher with their provided answers. Competing projects complicated the situation. According to PMs, a variety of other research institutes and development agencies offer different compensation amounts in areas for these activities, like Morogoro region.

Selection: Participant selection within the project led to conflicts. As the random sampling process used to select project participants was not well explained or understood by the majority of the interviewed LSs, the selection was perceived as unfair, with rumors spread about the Scale-N project participants. Frequent complaints and recurring attempts to explain the selection process disrupted the interventions and research activities. In one village, project participants were called "the affected ones," referring to the rumor that project participants were infected with HIV because they were selected for the project after participating in the baseline study that included a blood test. In another village, village officials tried to sneak relatives into the project, thereby ignoring the selection done by PMs. The demonstration site equipment was damaged and destroyed in two villages. PMs explained that this probably happened because project non-participants were jealous and disappointed that they were not selected, thus engaging in vandalism. These conflict causes were especially noticeable when destructive actions took place and project equipment was destroyed.

The following Figure 3 shows the category environment. The findings refer to external implications, circumstances, and natural conditions affecting the collaboration of LSs and PMs and resulting in conflict.

\subsubsection{Category: Environment}

Nature: Environment-related impacts, like floods, animals (eating the vegetables), pest-infected plants, and water shortages, challenged project success, thereby influencing the collaboration and creating collaboration conflicts. Water scarcity and pest infected vegetable plants are a pressing issue that challenges both project collaboration and project success. 
Infrastructure: Missing infrastructure like bridges and roads can make it impossible to reach the rural villages, thereby creating conflicts due to delayed implementation of activities. Being behind the project schedule might affect future activities.

Livelihood: LSs depend on farming activities as their primary source of food and income. Diverging priorities and high costs, through leaving the farm during the farming season, led to the outcome that some LSs could not participate in activities. Further, as LSs may be poorly educated, misunderstandings and difficult information transfer may occur.

\subsection{Identified Strategies that Prevented Conflict}

The second study objective was to identify strategies applied in the case study that could prevent conflict from occurring.

Three main strategies were identified.

\subsubsection{Involvement of Locals}

The involvement of LSs was perceived as important by PMs. PMs valued their inputs and involved LSs from the beginning of the project. PMs trained selected villagers to teach the rest of the project participants.

Additionally, LSs valued that their ideas, views, and comments were taken into account. For instance, the teachers in Chinoje provided their views about how parents with malnourished children might be able to access food for their children. In Mhenda, the village executive officer explained which types of vegetables might be accepted and helped find land for the demonstration site, later used by PMs for instruction and to show project participants how to set up their own pocket-garden. This information is vital for avoiding conflict in the first place and for designing the project with input from LSs and PMs.

\subsubsection{Development of Trust}

Furthermore, the creation of trust directly links to the collaboration with locals. LSs perceived the project to be trustworthy due to the collaborating with and involvement of village officials in the project design. The majority of LSs felt that using village structures and respecting village rules during the project helped to develop trust. Therefore, integrating local key persons, such as the village officials and the village administration, in the project design, proved vital for project acceptance.

Moreover, trust between LSs and PMs was fostered through sensitization activities designed to get to know each other and to explain the project's purpose and aims. Thus, not only were initial worries minimized, but also, trust was improved by showing and explaining to LSs their individual results from the baseline test. LSs mentioned worries that the blood was for HIV testing, but after receiving the results with an explanation, they stated they had increasing trust in the PMs. Lastly, building trust was supported by the continuing implementation of food upgrading strategies, providing tangible materials, like fruit trees and vegetable gardens, as well as knowledge transfer and nutrition education.

\subsubsection{Reducing the Language Barrier}

The collaboration with national staff reduced the risk of miscommunication. In the case study, national project members principally managed and visited the case study villages, interacting with the LSs. They were the most active PMs on the ground, regularly communicating with contact persons and supporting implementation activities in the villages. Tanzanian PMs spoke Swahili and could communicate with the majority of LSs. Thereby, PMs overcame language barriers that might result in conflict. Working with staff from the country of the research project allowed using their multi-lingual capacities for translation and moderation of activities and facilitated communication between foreign PMs and LSs. Several LSs stated that because translators guided the interviews and discussions, language was not an issue; thus, it was not perceived to be a cause of conflict. LSs seemed to trust local translators and facilitators, satisfied that somebody translated what they wanted to say. 


\section{Discussion}

The aim of this study was to identify conflict causes between the principle actors (project members and local stakeholders) in a complex trans- and inter-disciplinary, international research collaboration project. It identified and presented multiple conflict causes in a food security project at the project member-stakeholder nexus, which increased project complexity and needed to be considered during planning. Therefore, it supported the definition of transdisciplinary projects as complex organizations with an inherent high risk of conflict $[8,13]$. While multiple conflict drivers were identified that showed convergence with prior research, we argue that our research extrapolated additional drivers that are also crucial to consider when planning and implementing transdisciplinary projects in the context of sustainability research.

The findings corroborated, among others, the existence of conflict causes like inefficient communication and lack of explanations; unreliable and untimely project information; delayed and postponed meetings; as well as project specific causes like perceived injustices over the participant selection process; missing materials and unaffordable participation (shortage of resources); and inadequate compensation (reward system) $[12,13,25,28,29,47]$. Here, inadequate compensation refers to the rewards LSs received for carrying out research or implementation activities. International aspects, like language barriers, were mirrored in the conflict experiences of foreign PMs $[20,32,33]$.

In particular, applying the findings to a food security research project, this study found that overlaps of field project activities with seasonal farming activities of LSs that can result in a high non-attendance rate of farmers in project meetings; rumors due to the baseline blood testing to record and analyze the nutrition status; animals eating the vegetables; pest infections of plants that resulted in a loss of project resources or an inability to perform expected tasks; all have potential to be conflict drivers between the involved parties.

Case study site contextual factors also impacted the collaboration between LSs and PMs. The four case study villages were located in rural areas, where villagers were mainly dependent on agricultural production [34]. The village system and environment like geographically dispersed households, low socio-economic indicators, scarce resources, and natural disasters like floods and droughts in Sub-Saharan Africa $[34,35]$ challenge food security projects to perform well and lead to a tense and complex collaboration atmosphere between LSs and PMs. However, it is especially crucial for projects focusing on topics like food security to be approached with the integration of local stakeholders and a high diversity of disciplines. Applications and the testing of strategies take place on an interpersonal level. LSs and PMs need to collaborate and cooperate when working on food security issues.

\section{Prevention Strategies of Conflict Causes}

To reduce the risk of conflict, the last part of our discussions focuses on the mechanisms of conflict prevention applied in the case study project and discusses their potential for use in other comparative research projects. The consideration of conflict causes is relevant for careful planning and execution of future food security research projects. Moreover, the findings are also relevant for other types of projects incorporating a high degree of LS-PM interaction. Taking these conflict causes into account might reduce the risk of conflicts arising among the involved parties [48]. It is notable that most of the identified conflict causes between PMs and LSs could be addressed by engaging and applying the identified prevention strategies more deeply. This could support developing new methodological research collaboration approaches, meeting the needs of all involved actors, and supporting the project in achieving its goals. Moreover, there is the chance that improved collaboration positively affects the cost effectiveness of projects [31].

The next section discusses the key strategies that could be used to address identified conflict drivers, meaning that the findings will be combined to propose strategies for action (reducing the language barrier, development of trust, and involving locals). The identified prevention strategies are valuable when discussing how to implement new approaches for collaborations of north-south research cooperation. 
Regarding reducing the language barrier in the collaboration, the project mainly worked with Tanzanian staff to implement project activities in the villages. The local PMs were able to speak Swahili; thereby, language barriers were reduced, and communication was more efficient $[13,49]$. For international PMs, Tanzanian translators and facilitators supported the field activities and implementations.

For example, by focusing on reducing language barriers that cause conflict, it could be possible to address: (1) miscommunication; (2) the change of responses and unclear questions; and (3) protracted research activities for international PMs.

Research activities were mainly prolonged (3), due to miscommunication (1) and the change of responses or unclear questions (2). These interconnected conflict causes could be addressed or prevented by carefully considering the target group [50]. There is a need to address language obstacles more systematically within cross-language studies [51]. That can mean, for instance, turning complicated scientific language and complex issues into simplified questions [52] and adapting questions to the local vernacular. Local PMs might provide assistance. Field pilot phases are vital to eliminate or revise confusing questions [53-55]. Thereby, it is possible to prevent miscommunication, to avoid unclear questions, and to prevent protracted research activities.

The second identified conflict prevention strategy is the development of trust. Developing trust is crucial when working with local communities $[11,56]$. The conditions for trust development can be influenced [57]. It is argued that LSs who trust the project and its PMs are more likely to participate in the project, to collaborate, to provide crucial information, and to welcome international PMs visiting the villages. The identified activities that build trust include respecting and utilizing administrative village structures; involving village officials and other essential villagers in the project processes; engaging in sensitization activities; continuous implementation of activities; and leaving a mark in the villages. All these seem to help build trust in a collaboration relationship.

Engaging on a deeper level of trust development could minimize or mitigate the identified conflict causes, including: (1) receiving false information from LSs; (2) beliefs and rumors; and (3) LSs keeping traditional ways.

A collaborative atmosphere where everybody speaks freely must be developed. This means empowering LSs to speak up. LSs need to understand that there are no negative consequences if they report project disruptions or incidents. It is important to receive information about issues within the project, so that action can be taken to analyze and address the problem quickly.

Conflict causes due to beliefs and rumors (2) and LSs being resistant to change (3) could be addressed by deepening and reinforcing trust. If a certain level of trust is reached, it might be possible that LSs become more open minded, willing to test new things, or to approve and implement the project's strategies. Concerning beliefs and rumors (2), trust could support the collaboration in the sense that the LSs do not believe the rumors spread by non-participants.

Building trust on a deeper level is challenging in a collaborative research project. First, these research projects generally have short lifespans $[8,11,20]$, but building trust takes time and needs to be viewed as a permanent process [58], especially if international actors, who are not regularly in the villages, are involved. Like in other contexts, researchers may be perceived as "outsiders" and, thus, may not be welcomed, especially if their questions make the target group feel uncomfortable [59]. The duration of the project might not be long enough to develop the needed trust level.

Interpersonal sensitivity and soft skills are required to engage in trust building [13], which might be challenging for some scientific project staff members. First, they are often not trained in the matter. Second, there are no clear rules, and it is far more complicated than just writing scientific goals on a piece of paper.

In addition, previous collaboration experiences must be considered. LSs might have had negative experiences with other projects. On the other hand, there might be regions that have never experienced such collaborations or research projects. In these cases, developing strong trust probably takes more effort and special strategies [60]. 
Finally, the third and last identified key conflict prevention strategy was involving locals. Engaging with, and involving, LSs in the planning and implementation processes of the project positively affected the collaboration. It can also have positive effects on project success [61].

The involvement of LSs enabled the PMs to gather regional and village specific knowledge and information [23,62]. Further, LSs stated that they appreciated that their opinion and input was taken into account. Although the approach and process to involve LSs at a high level is challenging, it is argued that it benefits the whole project and, furthermore, might positively affect project sustainability, as community members contribute to solving their problems $[7,23,62-64]$.

Regional and village specific knowledge is essential for collaborative research projects [11,23], especially in the food security context. The project's participatory approach and its gathered information made it possible to achieve a high acceptance level of LSs. From the beginning, interactions supported the process of mapping relevant stakeholders, while pedagogical workshops helped to identify social structures and community constraints [23].

Nevertheless, it is argued that an even higher degree of involvement could address some of the identified conflict causes [56,63], namely: (1) LSs' dissatisfaction with their compensation amount; (2) expectations that PMs will solve all problems; (3) perceived injustice about the selection process; (4) insufficient project information; and (5) missing materials.

Although involving more locals more frequently might increase the project's organizational work, it may have perceptible positive effects [23,62]. The conflict causes of (1) LSs being dissatisfied with compensation and (2) diverging expectation about responsibilities could be directly addressed by increasing participant involvement. First, helping LSs realize that they are part of the project, that they own it, is important. Thus, they can keep and use its results (in this case, the extra produced vegetables, planted fruit trees, and knowledge transfer) well into the future, thus simultaneously making it more sustainable [62]. It is important that they inherently understand that the project belongs as much to them as to the PMs. When they feel in charge, they might not wait for PMs to solve problems, instead becoming active and creative, finding their own solutions, thus again making the project more sustainable in the long run. Further, the PMs need to accept and support this process [65]. The same argument works regarding dissatisfaction with the compensation. Some LSs explained that the information and knowledge they gained is more valuable than money, because the knowledge will stay and can be used after the money is gone. However, some LSs complained about their compensation. If the value is not obvious to everybody, it must be transparent. PMs need to make clear to the LSs not just the incentives and benefits, but also project ownership; repeatedly if necessary.

Conflicts due to the misunderstood selection process (3) and insufficient project information (4) could be addressed by implementing an efficient and transparent information transfer system. Ensuring that information regarding the project processes is easy to understand and regularly updated will keep LSs involved and empower them, which is argued to be vital for collaboration [62]. Facilitating frequent communication with involved actors will also help.

Lastly, conflict caused by LSs including missing materials (5) could also be addressed with an efficient and transparent information transfer system; LSs can inform PMs when they have difficulties purchasing, gathering, or obtaining the material needed.

However, it is important to recognize that there may be limits. New problems and conflicts could arise through intensified involvement of various LSs on different levels. Further, local communities are "heterogeneous entities with different power and social relationships" [62] (p.249) that might have various effects on the overall collaboration. Controversial priorities, interests, and perspectives among the LSs may affect the collaboration at the science-society intersection negatively. More research is needed to examine these impacts specifically. Overall, further empirical research is needed for integrating science into society $[13,23]$. It is of utter importance to conduct more empirical research at the science-society nexus to be able to support the process of co-creating knowledge and finding sustainable ways to deal with 21st Century challenges and complex issues, such as food security. Further case studies could help to verify the findings of this paper and support to improve the development of 
sustainable collaboration approaches for transdisciplinary research projects. Thereby, the involvement of local stakeholders from the project beginning should be a key component. Finally, regarding research limits, whilst this study found valuable new operational collaboration details, limitations apply. Language barriers must be considered as well as the possibility of bias in local stakeholders' and project members' responses. White, foreign, researchers conducted both the personal interviews and FGDs. Thus, answers might be affected by "desirable responding" [66] (p. 875). The whole picture must be considered, which means questioning who the researchers are and who provides information for the research. LSs may be reserved when talking about problems or challenges in connection with the project, especially when evaluating collaboration experiences in a setting addressing sustainable development and serious daily challenges like hunger [13]. Some LSs might have experienced intense conflicts, but did not feel empowered to talk. As villagers are, to a certain degree, dependent on external interventions, they might perceive it unwise to talk badly about the project and/or the collaboration [13]. They may be worried that there will be no follow-up or new project. Simultaneously, PMs might not feel confident enough to talk about conflict experiences. They need to engage in self-reflection about their own work, a task not everyone is open to do and also not trivial during a short interview. Moreover, as some PMs might already be used to the working conditions, they might no longer perceive certain superficial conflict causes, like LSs arriving late or not at all, as conflict. Therefore, they will not be mentioned during the interviews.

\section{Conclusions}

Overall, this study found that coordination, communication, and an efficient information transfer system between the principle actors-local stakeholders and project members-in a research project are critical for minimizing and preventing conflict. The identified strategies to prevent conflicts or facilitate their management include developing trust, reducing language barriers, and involving locals. Identified conflict causes were classified into these prevention strategies, showing how these conflict causes may be addressed and prevented.

It is argued that engaging consciously and strategically in these actions will facilitate collaboration at the science-society nexus. Actively implementing these strategies might result in synergies with project results: improved collaboration could positively affect the quality of collected data and project outcomes. It needs to be considered that implementing these strategies requires time to be properly realized. Therefore, longer project timeframes will benefit from efforts to establish a deeper collaborative relationship between the involved actors.

The findings extend the previous knowledge about collaboration conflicts within an international science-society collaboration project by highlighting the community voices about project failures and what are the limits of project implementation. In the context of transdisciplinary research projects, community perspectives are understudied so far. Knowledge on how much collaboration learning curves and variations in commitment affect the outcomes of collaborative projects is still marginal. With this paper, an understanding of communities' needs and structures was revealed to avoid conflict and project failures. Innovative collaboration approaches and methods that facilitate collaboration between stakeholders but also between stakeholders and project members are needed in order to be able to find sustainable solutions.

Creating awareness for the multiplicity of conflict drivers can be the first step towards more sensitized project planning. Further, the findings reveal practical operational details for consideration when working on food security issues with Tanzanian communities. Taking lessons from this case study and applying them to future projects focusing on food security is a good way to find innovative and sustainable solutions that reduce and prevent conflict in community-scientist collaborations.

Author Contributions: J.S.: development of the concept; literature research; development of methods; test design; data collection; data analysis; results discussion; and compiling the manuscript. K.L. and M.B.: development of the concept; literature research; development of methods; test design; results discussion; and compiling the manuscript. S.S.: development of the concept; and results discussion. 
Funding: Funding to support this research was provided by the Leibniz Centre for Agricultural Landscape Research ZALF e.V. PB2, AG SUSLAND. Eberswalder Straße 84. 15374 Müncheberg. We thank the collaboration of researchers from the Trans-Sec and Scale-N projects.

Acknowledgments: The findings are based on a master's thesis. The authors acknowledge the efforts of the Sokoine University staff members and their support while implementing this field research. We also thank all the participants in the communities and the translators for their valuable contribution. Further, we thank the Leibniz Centre for Agricultural Landscape Research (ZALF) for additionally supporting this publication. Finally, we also thank Ulrich Wurzel (HTW Berlin) for his support.

Conflicts of Interest: The authors declare no conflict of interest.

\section{References}

1. IPCC. Summary for Policymakers. In Climate Change 2013: The Physical Science Basis; Contribution of Working Group I to the Fifth Assessment Report of the Intergovernmental Panel on Climate Change; Stocker, T.F., Qin, D., Plattner, G.-K., Tignor, M., Allen, S.K., Boschung, J., Nauels, A., Xia, Y., Bex, V., Midgley, P.M., Eds.; Cambridge University Press: Cambridge, UK; New York, NY, USA, 2013.

2. IPCC. Summary for Policymakers. In Climate Change 2014: Impacts, Adaptation, and Vulnerability, Part A: Global and Sectoral Aspects; Contribution of Working Group II to the Fifth Assessment Report of the Intergovernmental Panel on Climate Change; Field, C.B., Barros, V.R., Dokken, D.J., Mach, K.J., Mastrandrea, M.D., Bilir, T.E., Chatterjee, M., Ebi, K.L., Estrada, Y.O., Genova, R.C., et al., Eds.; Cambridge University Press: Cambridge, UK; New York, NY, USA, 2014.

3. United Nations. The Millennium Development Goals Report 2015; United Nations: New York, NY, USA, 2015.

4. Todaro, M.P.; Smith, S.C. Economic Development, 12th ed.; Pearson: London, UK, 2015.

5. United Nations Framework Convention on Climate Change (UNFCCC). Elements of Adaptation. 2014. Available online: http://unfccc.int/focus/adaptation/items/6999.php (accessed on 5 November 2018).

6. Mohtar, H.R.; Lawford, R. Present and future of the water-energy-food nexus and the role of the community of practice. J. Environ. Stud. Sci. 2016, 6, 192-199. [CrossRef]

7. Mauser, W.; Klepper, G.; Rice, M.; Schmalzbauer, B.S.; Hackmann, H.; Leemans, R.; Moore, H. Transdisciplinary global change research: The co-creation of knowledge for sustainability. Curr. Opin. Environ. Sustain. 2013, 5, 420-431. [CrossRef]

8. Löhr, K.; Graef, F.; Bonatti, M.; Mahoo, H.F.; Wambura, J.; Sieber, S. Conflict management systems for large scientific research projects. Int. J. Confl. Manag. 2017, 28, 322-345. [CrossRef]

9. Daher, B.; Mohtar, R.H.; Pistikopoulos, E.N.; Portney, K.E.; Kaiser, R.; Saad, W. Developing Socio-Techno-Economic-Political (STEP) Solutions for Addressing Resource Nexus Hotspots. Sustainability 2018, 10, 512. [CrossRef]

10. Larrison, C.R. A Comparison of Top-down and Bottom-up Community Development Interventions in Rural Mexico: Practical and Theoretical Implications for Community Development Programs. University of Georgia, 1999. Available online: https://kb.osu.edu/dspace/bitstream/handle/1811/36912/112larrison-paper. pdf? sequence $=1$ (accessed on 16 September 2019).

11. Ross, L.F.; Loup, A.; Nelson, R.M.; Botkin, J.R.; Kost, R.; Smith, G.R.; Gehlert, S. The Challenges of Collaboration for Academic and Community Partners in a Research Partnership: Points to Consider. J. Empir. Res. Hum. Res. Ethics 2010, 5, 19-31. [CrossRef] [PubMed]

12. Moura, H.; Teixeira, J.C. Managing Stakeholders Conflicts; Wiley Online Library: Hoboken, NJ, USA, 2010; Chapter 17. [CrossRef]

13. Löhr, K.; Weinhardt, M.; Schütt, J.; Bonatti, M.; Graef, F.; Sieber, S. Transdisciplinary research in sustainable development projects: analyzing collaboration experience at the society-science nexus. Dev. Pract. 2019, in press.

14. Adler, N.; Elmquist, M.; Norrgren, F. The challenge of managing boundary-spanning research activities: Experiences from the Swedish context. Res. Policy 2009, 38, 1136-1149. [CrossRef]

15. Gebert, D.; Rosenstiel, L. Organisationspsychologie. 4. Auflage; Kohlhammer Verlag: Stuttgart, Germany, 1996.

16. Glasl, F. Konfliktmanagement-Ein Handbuch für Führungskräfte, Beraterinnen und Berater. 11. aktualisierte Auflage; Haupt Verlag, Verlag Freies Geisteleben Stuttgart: Stuttgart, Germany, 2013.

17. Saundry, R. Conceptualizing Workplace Conflict and Conflict Management. In Reframing Resolution; Springer: Berlin/Heidelberg, Germany, 2016; pp. 13-33. 
18. Wall, J.A.; Callister, R.R. Conflict and Its Management. J. Manag. 1995, 21, 515-558. [CrossRef]

19. Rahim, M.A. Toward a theory of managing organizational conflict. Int. J. Confl. Manag. 2002, 13, $206-235$. [CrossRef]

20. Löhr, K.; Hochmuth, C.; Graef, F.; Wambura, J.; Sieber, S. Conflict management programs in trans-disciplinary research projects: The case of a food security project in Tanzania. Food Secur. 2016, 9, 1189-1201. [CrossRef]

21. Sturm, A.; Opterbeck, I.; Gurt, J. Organisationspsychologie. 1. Auflage, Wiesbaden: VS Verlag für Sozialwissenschaften; Springer: Berlin/Heidelberg, Germany, 2011.

22. Gyan, C.; Ampomah, A.O. Effects of Stakeholder Conflicts on Community Development Projects in Kenyase. SAGE Open 2016, 6, 2158244016635254. [CrossRef]

23. Bonatti, M.; Schlindwein, I.; Lana, M.; Bundala, N.; Sieber, S.; Rybak, C. Innovative educational tools development for food security: Engaging community voices in Tanzania. Futures 2018, 96, 79-89. [CrossRef]

24. Scale-N. Structure, Members. 2018. Available online: http://www.scale-n.org/user (accessed on 16 September 2019).

25. Rosenstiel, L.; Nerdinger, F.W. Grundlagen der Organisationspsychologie-Basiswissen und Anwendungshinweise. 7. Auflage; Schäffer-Poeschel Verlag: Nördlingen, Germany, 2011.

26. Marcus, B. Einführung in die Arbeits—und Organisationspsychologie. 1. Auflage. Wiesbaden: VS Verlag für Sozialwissenschaften; Springer Fachmedien Wiesbaden GmbH: Berlin/Heidelberg, Germany, 2011.

27. Nerdinger, F.W.; Blickle, G.; Schaper, N. Arbeits und Organisationspsychologie; Springer: Berlin/Heidelberg, Germany, 2014.

28. Pinto, J.K.; Kharbanda, O.P. Project management and conflict resolution. Proj. Manag. J. 1995, 26, 45-54.

29. Botha, J. Chapter 7-Conflict Management in the Establishment of Ten South African Outreach Nurseries. 2007. Available online: http://wiredspace.wits.ac.za/bitstream/handle/10539/2095/Ch7.pdf;jsessionid= 40D8CBB90E5D65D514E9FFEA6B4366BD?sequence=13 (accessed on 6 November 2019).

30. Luton, R.; Jordaan, T.; Hildbrand, S.; Proches, C.G.; Sitshaluza, A.; Dominy, J.; Ntshinga, W.; Moloto, N.; Pade-Khene, C. Complexity of Stakeholder Interaction in Applied Research. Ecol. Soc. 2013, 18, 13.

31. Danielsen, F.T.; Adrian, S.; Brofeldt, M.; Noordwijk, M.K.; Poulsen, S.; Rahayu, E.; Rutishauser, I.; Theilade, A.; Widayati, N.; Nguyen Bang, A.; et al. Community Monitoring for REDD+: International Promises and Field Realities. Ecol. Soc. 2013, 18. [CrossRef]

32. Blom, H.; Meier, H. Interkulturelles Management, 3. überarbeitete und erweiterte Auflage; NWB Verlag GmbH \& Co. KG.: Herne, Germany, 2017.

33. Gronwald, K. Chapter 7-Conflict Management in International Projects, Global Communication and Collaboration; Springer: Berlin/Heidelberg, Germany, 2017.

34. Food and Agriculture Organization of the United Nations (FOA). FOA in Tanzania-Tanzania at a Glance. 2019. Available online: http://www.fao.org/tanzania/fao-in-tanzania/tanzania-at-a-glance/en/ (accessed on 6 November 2019).

35. El Bilali, H.; Callenius, C.; Strassner, C.; Probst, L. Food and nutrition security and sustainability transitions in food systems. Food Energy Secur. 2018, 8, e00154. [CrossRef]

36. Bao, Y.; Zhu, F.; Hu, Y.; Cui, N. The Research of Interpersonal Conflict and Solution Strategies. Psychology 2016, 7, 541-545. [CrossRef]

37. Karimova, S.L. Prevention of Interpersonal Conflicts in Teenagers' Environment. Procedia Soc. Behav. Sci. 2015, 191, 1843-1847. [CrossRef]

38. Johl, S.K.; Renganathan, S. Strategies for Gaining Access in Doing Fieldwork: Reflection of two Researchers. Electron. J. Bus. Res. Methods 2010, 8, 42-50.

39. Reif, C.; Siebert, S. Scaleing Up Nutrition: Implementing Potentials of Nutrition-Sensitive and Diversified Agriculture to Increase Food Security. 2016. Available online: https://susland.zalf.de/scale-n/ (accessed on 6 November 2019).

40. Bundesministerium für Ernährung und Landwirtschaft (BMEL) Nutrition-Diversified Agriculture for a Balanced Nutrition in Sub-Saharan Africa, Project Profile Scaling-up Nutrition: Implementing Potentials of Nutrition Sensitive and Diversified Agriculture to Increase Food Security. 2013. Available online: https://www.bmel.de/EN/Agriculture/Global-Food-Situation-FOA/_Texte/Diversified_agriculture_ for_balanced_nutrtition_Sub-Saharan_Africa.html/ (accessed on 18 February 2019).

41. Freire, P. Pedagogy of the Oppressed; Continuum: New York, NY, USA, 2000. 
42. Helfferich, C. Die Qualität qualitativer Daten-Manual für die Durchführung qualitativer Interviews; Springer: Berlin/Heidelberg, Germany, 2005.

43. Niemiec-Knas, M. Qualitative Interviews in der Fremdsprachenforschung. 2014. Available online: http: //dlibra.bg.ajd.czest.pl:8080/Content/2102/8.pdf (accessed on 6 November 2019).

44. Ullrich, P. Das explorative ExpertInneninterview:Modifikationen und konkrete Umsetzung der Auswertung von ExpertInneninterviews nach Meuser/Nagel. In Die Transformation des Politischen: Analysen, Deutungen und Perspektiven. Siebentes und achtes DoktorandInnenseminar der Rosa-Luxemburg-Stiftung; Engartner, T., Kuring, D., Teubl, T., Eds.; Dietz: Berlin, Germany, 2006; pp. 100-109. ISBN 978-3-320-02105-4.

45. Imas, L.G.M.; Rist, R.C. The Road to Results-Designing and Conducting Effective Develpoment Evaluations; The International Bank for Reconstruction and Development/The World Bank: Washington, DC, USA, 2009.

46. Schütt, J. Conflict Experience in Collaborative Research at the Intersection of Local Stakeholder and Project Team Members-The Case of a Food Security Project in Tanzania. Master's Thesis, University of Applied Sciences, Berlin, Germany, 2018.

47. Ding, R. Key Project Management Based on Effective Project Thinking. In Resolve Project Conflicts; Springer: Berlin/Heidelberg, Germany, 2016. Chapter 12. [CrossRef]

48. Guan, D. Conflicts in the Project Environment. Paper presented at PMI ${ }^{\circledR}$ Global Congress 2007-Asia Pacific, Hong Kong, People's Republic of China. Newtown Square, PA: Project Management Institute. 2007. Available online: https://www.pmi.org/learning/library/project-environment-eleven-project-conflicts-7348\% 20/ (accessed on 16 September 2019).

49. Lee, S.K.; Sulaiman-Hill, C.R.; Thompson, S.C. Overcoming language barriers in community-based research with refugee and migrant populations: options for using bilingual workers. BMC Int. Heal. Hum. Rights 2014, 14, 11. [CrossRef]

50. Iarossi, A. The Power of Survey Design—A User's Guide for Managing Surveys, Interpreting Results, and Influencing Respondents; The International Bank for Reconstruction and Development/The World Bank: Washington, DC, USA, 2006. [CrossRef]

51. Squires, A. Methodological challenges in cross-language qualitative research: A research review. Int. J. Nurs. 2009, 46, 277-287. [CrossRef] [PubMed]

52. Kruse, J. Reader zum Seminar: Einführung in die qualitative Sozialforschung/Biografieforschung, Sommersemester 2004 at the University Freiburg. Institute for Sociology, 2004. Available online: http://www.uni-koeln.de/hf/konstrukt/didaktik/biografiearbeit/seminarreader\%20biographiearbeit\% 20unu\%20biographieforschung.pdf (accessed on 13 February 2019).

53. Mieg, H.A.; Brunner, B. Experten Interviews eine Einführung und Anleitung; ETH Zürich, Research Collection: Zurich, Switzerland, 2001. [CrossRef]

54. Reynolds, N.; Diamantopoulos, A.; Schlegelmilch, B. Pre-Testing in Questionnaire Design: A Review of the Literature and Suggestions for Further Research. Mark. Res. Soc. J. 1993, 35, 1-11. [CrossRef]

55. Bradburn, N.M.; Sudman, S.; Wansink, B. Asking Questions, The Definitive Guide to Questionnaire Design-For Market Research, Political Polls, and Social and Health Questionnaires; John Wiley \& Sons, Inc. Jossey-Bass: San Francisco, CA, USA, 2004.

56. Anaquot, K. Collaborative Research: an "Indigenous Lens" Perspective. Canadian Coalition for Global Health Research (CCGHR), 2008. Available online: http://www.ccghr.ca/wp-content/uploads/2013/04/ IndigenousLens_GIHR_2008_en.pdf (accessed on 11 September 2019).

57. Möllering, G. Cultivating the field of trust research. J. Trust. Res. 2017, 7, 107-114. [CrossRef]

58. Feldman, M.; Bell, J.; Berger, M. Gaining Access: A Practical and Theoretical Guide for Qualitative Researchers; California AltaMira Press: Walnut Creek, CA, USA, 2003; ISBN 0-7591-0216-3.

59. Okumus, F.; Altinay, L.; Roper, A. Gaining Access for Research-Reflections from Experience. Ann. Tour. Res. 2007, 34, 7-26. [CrossRef]

60. Thomson, S.; Ansoms, A.; Murison, J. Emotional and Ethical Challenges for Field Research in Africa-The Story behind the Findings; Palgrave Macmilan: London, UK, 2013; ISBN 978-1-137-26374-2.

61. Silvius, G.A.J.; Schipper, R. Exploring the relationship between sustainability and project success-conceptual model and expected relationships. Int. J. Inf. Syst. Proj. Manag. 2016, 4, 5-22. [CrossRef]

62. Mubita, A.; Libati, M.; Mulonda, M. The Importance and Limitations of Participation in Development Projects and Programmes. Eur. Sci. J. ESJ 2017, 13, 238-251. [CrossRef] 
63. Chambers, R. Rural Appraisal: Rapid, Relaxed and Participatory; IDS Discussion Paper 311; Institute of Development Studies: Brighton, UK, 1992.

64. Hadorn, G.H.; Bradley, D.; Pohl, C.; Rist, S.; Wiesmann, U. Implications of transdisciplinarity for sustainability research. Ecol. Econ. 2006, 60, 119-128. [CrossRef]

65. Israel, B.A.; Schulz, A.J.; Parker, E.A.; Becker, A.B. Community-based Participatory Research: Policy Recommendations for Promoting a Partnership Approach in Health Research. CCPH Special Section. Educ. Health 2001, 14, 182-197.

66. Tourangeau, R.; Yan, T. Sensitive Questions in Survey. Am. Psychol. Assoc. 2007, 1333, 859-883. [CrossRef]

(C) 2019 by the authors. Licensee MDPI, Basel, Switzerland. This article is an open access article distributed under the terms and conditions of the Creative Commons Attribution (CC BY) license (http://creativecommons.org/licenses/by/4.0/). 